\title{
Effect of Material Variability and Mechanical Eccentricity on the Seismic Vulnerability Assessment of Reinforced Concrete Buildings
}

\author{
Mario Lucio Puppio ${ }^{1, *}$, Martina Pellegrino ${ }^{1, *}$, Linda Giresini ${ }^{1}$ (D) and Mauro Sassu ${ }^{2}$ \\ 1 Department of Energy, Systems, Territory and Construction Engineering; University of Pisa, Pisa 56126, Italy; \\ linda.giresini@unipi.it \\ 2 Department of Civil, Environmental Engineering and Architecture, University of Cagliari, 09123 Cagliari, \\ Italy; msassu@unica.it \\ * Correspondence: mariolucio.puppio@ing.unipi.it (M.L.P.); martina.pellegrino@gmail.com (M.P.); \\ Tel.: +39-050-2218204 (M.L.P.)
}

Received: 11 April 2017; Accepted: 14 July 2017; Published: 26 July 2017

\begin{abstract}
The present paper deals with the influence of material variability on the seismic vulnerability assessment of reinforced concrete buildings. Existing r.c. buildings are affected by a strong dispersion of material strengths of both the base materials. This influences the seismic response in linear and nonlinear static analysis. For this reason, it is useful to define a geometrical parameter called "material eccentricity". As a reference model, an analysis of a two storey building is presented with a symmetrical plan but asymmetrical material distribution. Furthermore, an analysis of two real buildings with a similar issue is performed. Experimental data generate random material distributions to carry out a probabilistic analysis. By rotating the vector that defines the position of the center of strength it is possible to describe a strength domain that is characterized by equipotential lines in terms of the Risk Index. Material eccentricity is related to the Ultimate Shear of non-linear static analyses. This relevant uncertainty, referred to as the variation of the center of strength, is not considered in the current European and Italian Standards. The "material eccentricity" therefore reveals itself to be a relevant parameter to considering how material variability affects such a variation.
\end{abstract}

Keywords: material variability; strength domain; seismic assessment of r.c. buildings; nonlinear static analysis

\section{Introduction}

Reinforced Concrete buildings built during the 40-70s are affected by a large dispersion of mechanical properties, especially when concrete is considered. This is due to (1) the inadequate mix-design of concrete (with a huge dispersion of water-concrete ratio); (2) the use of unwashed or low quality aggregates; (3) the lack of automation and control of the concrete production; (4) ineffective procedures for the concrete casting batch and vibration [1,2]. This dispersion can be quantified through the definition of a geometrical parameter called material eccentricity [3,4]. Also, other parameters had a great relevance in the seismic evaluation of existing structures e.g., the geometry of the bearing elements, the aging of the concrete, corrosion, the type of subsoil [5-8].

The building characterization $[9,10]$ has great relevance, in particular, to the seismic vulnerability assessment [11], in which non-structural elements also play a relevant role [12-14]. According to previous experiences on the monitoring and rehabilitation of existing buildings [4,15-17] it is possible to notice significant uncertainties in the mechanical properties of both concrete and steel bars. Innovative and traditional techniques - in particular, additional reinforcement [18,19], are not able to cover all these uncertainties. The tendency of the current Standards, e.g., [20], is to penalize the mean value 
of the materials' strength with a specific "confidence factor" depending on the available information. This approach does not take into account the real distribution of the mechanical values, together with their standard deviation in material tests [21].

Nevertheless, the tendency to carry out a probabilistic analysis of existing buildings through the assessment of the uncertainties modelled with random and epistemic variables might imply analytical complications. A significant analysis can be the assessment of a material eccentricity, which induces two different effects: eccentricity of stiffness and eccentricity of strength. In the present paper both aspects are analysed.

The effects of spatial variability of concrete and steel strength are considered in this paper for typical Italian r.c. buildings. Firstly, the effect of material variability on the strength domains of the usual failure mechanisms is evaluated in Section 2, according to [22]. Those domains are related to eccentric axial force and shear for beams and columns [23]. After that, the effects of changing strength and stiffness are investigated through two simple benchmark buildings (Section 3). Section 4 then illustrates the possible failure mechanisms that can occur in r.c. buildings affecting material variability. This issue is applied to a real structure in Section 5: the school of Don Bosco in an Italian city. This structure was subjected to a set of experimental tests addressed to seismic retrofitting. The material eccentricity is evaluated in non-linear static analyses. Random distributions of strength are considered to obtain fragility curves. This method highlights the way to achieve a probabilistic estimation of the structural safety level for similar buildings.

\section{Centre of Strength and Centre of Stiffness}

\subsection{Generalities}

The European seismic code [20] generally considers in-plan irregularity throughout the eccentricities of the equivalent seismic forces. Also, non-uniform distribution of the columns material in r.c. buildings can produce torsional effects [24-27]: hence the definition of "material eccentricity" $e_{m}$. Conventional analyses on existing buildings generally consider uniform materials by assuming an average value obtained from an experimental test. Taking into account the material variability, even just for columns, produces a sensitive variation in the response of the model both in nonlinear and linear analyses. In this paragraph, the eccentricities of stiffness and of strength, deriving from the material eccentricity are illustrated.

\subsection{Center of Stiffness and Eccentricity of Stiffness}

In a linear elastic analysis the coordinates of the center of stiffness are [28]:

$$
\begin{aligned}
& x_{s, j}=\frac{\sum_{i}^{n} x_{i} K_{y i}}{\sum_{i}^{n} K_{y i}} \\
& y_{s, j}=\frac{\sum_{i}^{n} y_{i} K_{x i}}{\sum_{i}^{n} K_{x i}}
\end{aligned}
$$

where:

$x_{i}, y_{i}$ coordinates of the $i$-th column;

$K_{x i}(E), K_{y i}(E)$ stiffness of the $i$-th column in the coordinate directions, the function of the Young modulus E. Because of this definition, the center of the stiffness position is affected by material variability through $\mathrm{E}$ values. The elastic modulus is related to the concrete compressive strength with the following expression [20]:

$$
E_{c}=22,000\left(\frac{f_{c}}{10}\right)^{0.3}
$$

The stiffness eccentricity in $x$ and $y$ directions $e_{s x, j}$ and $e_{s x, j}$. is given by these ratios: 


$$
\begin{aligned}
& e_{s x, j}=\frac{x_{s, j}-x_{c, j}}{L_{x}} \\
& e_{s y, j}=\frac{y_{s, j}-y_{c, j}}{L_{y}}
\end{aligned}
$$

$x_{c}, y_{c}$ coordinates of centroid of the $j$-th floor;

$L_{x}, L_{y}$ building length in $x$ and $y$ directions.

\subsection{Centre of Strength and Eccentricity of Strength}

The collapse of R.C. columns depends on:

1. The strength of the concrete;

2. The strength of steel bars;

3. The position of the columns in the building;

4. The geometry (length, restraints, and inertial characteristics) of the columns.

Two possible criteria to define, in a simple way, the center of strength are here described: the first one is related to collapse caused by compression force (method 1), the second one by bending moment (method 2).

Method 1. The center of compressive strength of $n$ columns at the $j$-level is calculated by a weighted average of the axial compression resistance of the columns with respect to their in plan positions.

$$
\begin{gathered}
x_{R}^{C}=\frac{\sum_{i}^{n} N_{u, i} x_{i}}{\sum_{i}^{n} N_{u, i}} \\
y_{R}^{C}=\frac{\sum_{i}^{n} N_{u, i} y_{i}}{\sum_{i}^{n} N_{u, i}}
\end{gathered}
$$

$N_{u, i}$ compressive axial resistance of the $i$-th columns;

$x_{i}, y_{i}$ coordinates of the $i$-th columns;

$n$ number of columns at $j$-th level.

Method 2. The center of bending strength is calculated by a weighted average of the ultimate bending moment of the columns with respect to their in-plan positions.

$$
\begin{aligned}
& x_{R, j}=\frac{\sum_{i}^{n} M_{u, i} x_{i}}{\sum_{i}^{n} M_{u, i}} \\
& y_{R, j}=\frac{\sum_{i}^{n} M_{u, i} y_{i}}{\sum_{i}^{n} M_{u, i}}
\end{aligned}
$$

where:

$M_{u, i}$ failure bending moment of the R.C. section of the $i$-th column.

The corresponding strength eccentricity is:

$$
\begin{aligned}
& e_{R x, j}=\frac{x_{R, j}-x_{c, j}}{L_{x}} \\
& e_{R y, j}=\frac{y_{R, j}-y_{c, j}}{L_{y}}
\end{aligned}
$$

where:

$x_{R j}, y_{R j}$ coordinates of the center of strength, computed with Method 1 or Method 2;

$x_{c j}, y_{c j}$ coordinate of the $j$-th column;

$L_{x}, L_{y}$ building length in $x$ and $y$ directions. 


\section{A Benchmark Case-Study}

\subsection{Description of the Benchmark Building}

A simply two storey R.C. frame (Figure 1) is analyzed here as a benchmark example. The in-plan dimension of the building is $7.35 \mathrm{~m} \times 6.45 \mathrm{~m}$. This model is composed of six columns for each floor of cross section $40 \times 40 \mathrm{~cm}^{2}$ and $\mathrm{n}$. 4 steel bars with a diameter of $20 \mathrm{~mm}$ for each one. The beams have a cross section of $40 \times 50 \mathrm{~cm}^{2}$. The following assumptions are made to highlight the effect of material variability:

- Uniform material distribution (u.m.d.);

- Non-uniform material distribution (n.u.m.d.);

- Flexible slab, simulated by assuming equivalent bracing of axial stiffness $K_{B}=3000 \mathrm{kN} / \mathrm{cm}$;

- Rigid slab, obtained through kinematic restraints at the diaphragm level.

The assumed R.C. mechanical properties are listed in Table 1. Linear and nonlinear static analyses are compared to evaluate the seismic response. All the analyses are performed with FEM Software Midas GEN (ver. 2016 release 2.1, MIDAS Information Technology, Gyeonggi-do 13487, Korea).

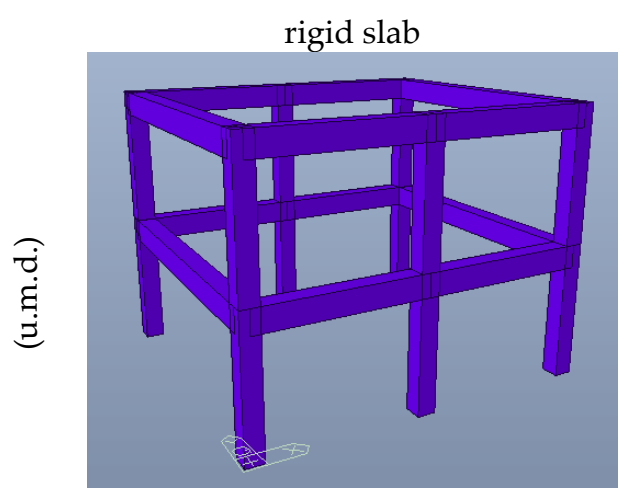

(a)

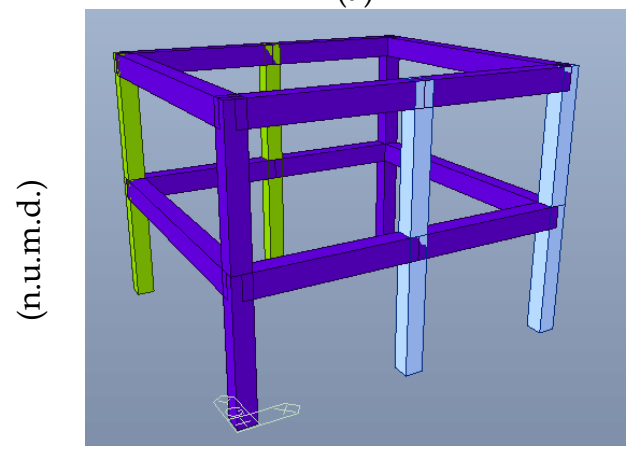

(c)

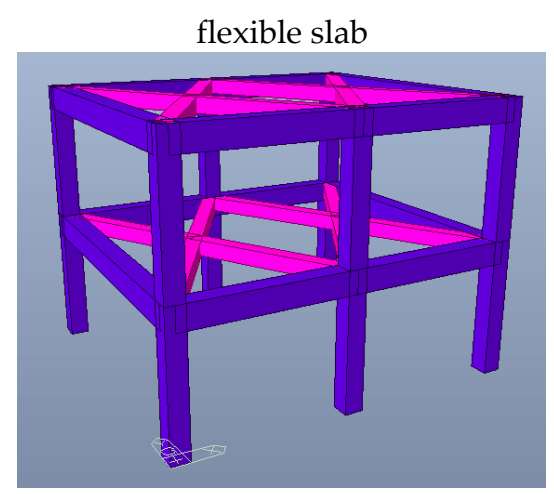

(b)

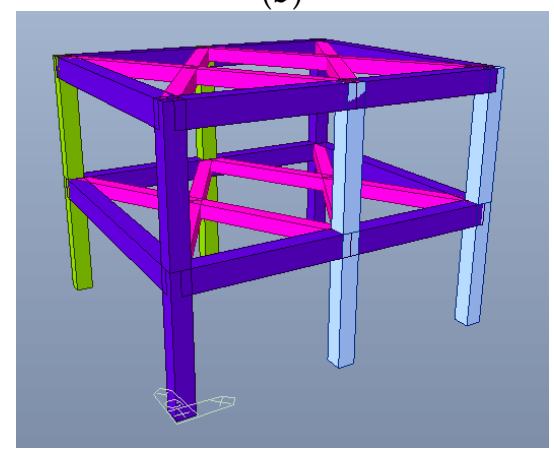

(d)

Figure 1. Main views of the benchmark finite element models: rigid slabs (a,c); flexible slabs (b,d).

Table 1. Mechanical characteristics of the benchmark model.

\begin{tabular}{ccccc}
\hline Material Number & $f_{\mathcal{c}} \mathbf{( M P a )}$ & $\left.E_{c} \mathbf{( M P a}\right)$ & $\left.f_{y} \mathbf{( M P a}\right)$ & Color \\
\hline 1 & 10 & 22,000 & 230 & Ciano \\
2 & 20 & 27,085 & 290 & Blue \\
3 & 30 & 30,590 & 350 & Green \\
4 & 20 & 13,542 & 290 & Magenta \\
\hline
\end{tabular}

The assigned strength distribution causes material eccentricity. 
Table 2 are calculated through the criterion of bending collapse (Equations (8) and (9)).

Table 2. Material eccentricity of the benchmark model with percentage of the total building length in the corresponding direction.

\begin{tabular}{cccc}
\hline Material Eccentricity & $\boldsymbol{x}$ & $\boldsymbol{y}$ & Units \\
\hline$e_{m}$ & 61 & 108 & $\mathrm{~cm}$ \\
& 8.3 & 16.7 & $\%^{1}$ \\
\hline
\end{tabular}

${ }^{1}$ Material eccentricity ratio main dimensions of the building.

Both linear and non-linear analyses are performed by applying the seismic action in the X direction Ultimate Limit State ULS for the models of Figure 1. The results in terms of elastic displacements and rotations are reported in Table 3.

Table 3. Summary of results.

\begin{tabular}{|c|c|c|c|c|c|c|c|c|c|}
\hline \multicolumn{2}{|c|}{ Types of Analysis } & \multicolumn{4}{|c|}{ Rigid Slab } & \multicolumn{4}{|c|}{ Flexible Slab } \\
\hline & & $D_{u}-D_{y}$ & $\varphi_{u}-\varphi_{y}$ & $C / D$ & $I_{R}$ & $D_{u}-D_{y}$ & $\varphi_{u}-\varphi_{y}$ & $C / D$ & $I_{R}$ \\
\hline \multirow{2}{*}{ (uniform) } & Linear & 0.722 & 0.000 & - & 0.45 & 0.72 & 0.000 & - & 0.45 \\
\hline & n-Linear & 7.840 & 0.000 & 0.82 & 0.76 & 7.96 & 0.000 & 0.82 & 0.76 \\
\hline \multirow{2}{*}{ (n-uniform) } & Linear & 0.680 & 0.005 & - & 0.40 & 0.71 & 0.030 & - & 0.38 \\
\hline & n-Linear & 6.840 & 0.020 & 0.77 & 0.76 & 7.05 & 0.020 & 0.79 & 0.76 \\
\hline
\end{tabular}

The symbols of Table 3 are so defined:

$D_{u}-D_{y}$ Elastic displacement ULS (Ultimate Limit State) for Linear Analysis (LA) or target displacement for Non Linear Analysis (NLA).

$\varphi_{u}-\varphi_{y}$ Elastic rotation corresponding to ULS for LA, target rotation for NLA.

$C / D$ Max. Capacity/Demand ratio for bending mechanism. For LA it is the ratio $M_{E d} / M_{R d}$, while for NLA the ratio is $\theta / \theta_{u} . \theta_{u}$ is the floor rotation corresponding to the achievement of the ultimate condition. $M_{R d}$ is defined in Section 3.2.

\subsection{Calculation of the Risk Index}

The Risk Index is calculated according to [29] as:

$$
I_{R}=\frac{P G A_{C}}{P G A_{D}}
$$

PGA $_{C}$ is the collapse capacity derived from the push-over analysis; PGA $A_{D}$ is the demand in terms of peak ground acceleration as mentioned in the Eurocode 8 [20]. For the models with flexible slab, displacements and rotations of the plan are evaluated as the average value at the top of each column.

It is well known that linear analysis furnishes more severe Risk Indexes $I_{R}$ than the non-linear one, as also shown in the benchmark model. It is also relevant to point out that irregular material distribution in the plan also produces torsional effects also for a symmetric building such as the benchmark building; that occurs in both analyses, due to strength eccentricity. Moreover, it is important to observe that $I_{R}$ and the ultimate shear strength of the columns are not influenced by the local variation of strength in LA or NLA as suggested by Eurocode 8 [20]. It is a consequence of their dependence only on the average mechanical properties of the columns. In other terms, material eccentricity involves torsional modes [27,30] as well as a geometric eccentricity but this aspect is not discussed in the current Standards [20]. The multimodal and adaptive pushover appear the most suitable methods to consider torsional effects here induced [31,32]. A comparison of the traditional model with uniform (u.m.d.) and the model with non-uniform material distributions (n.u.m.d.) in the benchmark example highlights that: 
1. In-plane displacements and rotations are greater for (n.u.m.d.), inducing additional stresses on the external columns;

2. The maximum ratio between capacity and demand decreases for (n.u.m.d.);

3. The ultimate shear does not have relevant changes because it is related to the mean resistance of the structure, that does not sensitively vary in average terms;

4. The ultimate displacement decreases for (n.u.m.d.) compared to (u.m.d.).

This leads to a reduction of the risk index in linear analysis, which is more noticeable for the models with flexible slabs. The same effects are also evaluated in Section 4 on a real case-study.

\section{Effects of Material Variability on Collapse Mechanisms}

\subsection{Input Parameters and Failure Mechanisms for Parametric Analysis}

The recurring mechanical properties of the typical r.c. existing structures built in Italy in the 1960s are listed below. The yield stress of steel bars used in the present analysis are reported in Table 4 and are taken from [33].

Table 4. Yield strength of steel type AQ42, AQ50 and AQ60 [33].

\begin{tabular}{ccccc}
\hline Steel Strength & AQ42 & AQ50 & AQ60 & Units \\
\hline $\mathrm{f}_{\mathrm{y}, \min }$ & 265.0 & 282.4 & 353.7 & $\mathrm{~N} / \mathrm{mm}^{2}$ \\
$\mathrm{f}_{\mathrm{y} \cdot \operatorname{med}}$ & 325.4 & 369.9 & 432.6 & $\mathrm{~N} / \mathrm{mm}^{2}$ \\
$\mathrm{f}_{\mathrm{y} \cdot \max }$ & 397.4 & 530.0 & 560.8 & $\mathrm{~N} / \mathrm{mm}^{2}$ \\
$\sigma$ & 23.17 & 29.45 & 36.59 & $\mathrm{~N} / \mathrm{mm}^{2}$ \\
\hline
\end{tabular}

Similarly, the concrete cubic compression strength used here is listed in Table 5.

Table 5. Concrete cubic compression strength from experimental in situ tests.

\begin{tabular}{ccccc}
\hline Cubic Compression Strength & ${\text { Test } \mathbf{A}^{\mathbf{1}}}$ & Test B $^{\mathbf{2}}$ & Test C $^{\mathbf{2}}$ & Units \\
\hline $\mathrm{R}_{\mathrm{c} \text { min }}$ & 7.0 & 21.9 & 29.6 & $\mathrm{~N} / \mathrm{mm}^{2}$ \\
$\mathrm{R}_{\mathrm{c} \text { mean }}$ & 26.0 & 37.3 & 38.2 & $\mathrm{~N} / \mathrm{mm}^{2}$ \\
$\mathrm{R}_{\mathrm{c} \text { max }}$ & 45.0 & 40.1 & 46.7 & $\mathrm{~N} / \mathrm{mm}^{2}$
\end{tabular}

${ }^{1}$ secondary school Don Bosco in Francavilla in Sinni (Potenza-Italy); ${ }^{2}$ secondary school Francesco Carrara in Lucca (Lucca-Italy).

The failure mechanism, due to transverse forces, often involves collapse of the columns at the ground floor. In fact, in the common practice without considering the seismic action, as done for many existing R.C. structures built in the 1960s, the columns were loaded by axial forces due to vertical loads, together with bending and shear due to transverse wind loads. In most cases, no variation in geometric section along the height of the buildings was considered. The collapse bending moment in r.c. columns is given by Eurocode 2 (for symbols see Appendix A or BS EN 1992-1-1 2004):

$$
M_{R d, B}=N_{E d}\left(\frac{h}{2}-\frac{k}{\beta \cdot b \cdot \alpha \cdot f_{c d}} N_{E d}\right)+A_{s}(h-2 \cdot c) f_{y d}
$$

The corresponding shear strength is:

$$
\begin{gathered}
V_{R d, c}=\left[C_{R d, c} k\left(100 \rho_{l} f_{c k}\right)^{1 / 3}+k_{1} \sigma_{c p}\right] b_{w} d \\
V_{R d, s}=\frac{A_{s w}}{s} z f_{y w d} \cot \theta \\
V_{R d, \max }=\alpha_{c w} b_{w w} z v_{1} f_{c d} /(\cot \theta+\tan \theta)
\end{gathered}
$$


The ultimate shear resistance of the section $V_{R d}$ is:

$$
V_{R d}=\min \left(V_{R d, c}, V_{R d, s}, V_{R d, \max }\right)
$$

From which, the collapse bending moment of a column with height $h_{i}$ is:

$$
M_{R d, T}=\frac{V_{R d} h_{i}}{\alpha}
$$

where:

$h_{i}$ is the height of the $i$-th column.

$\alpha$ is taken equal to 2 for slender elements and 1 for the squat ones (see Table 6). The slenderness is defined as:

$$
\lambda=\frac{h_{i}}{h_{s}}
$$

being $h_{s}$ the height of the cross section.

The collapse occurs when the minimum value between $M_{R d, B}$ and $M_{R d, T}$ is attained.

In the following case, three types of columns are analysed: (a) $40 \times 40 \mathrm{~cm}^{2}$; (b) $40 \times 70 \mathrm{~cm}^{2}$; (c) $40 \times 180 \mathrm{~cm}^{2}$ (Figure 2) varying once the concrete and the steel strength, considering both flexural and shear failures as in Table 6. The curves are also related to different values of axial force $N_{E d}$ consistent with the design criteria adopted during the 1960s. A set of reasonable "historical" strength values (Table 7) for concrete and steel are then assigned to the structural elements.
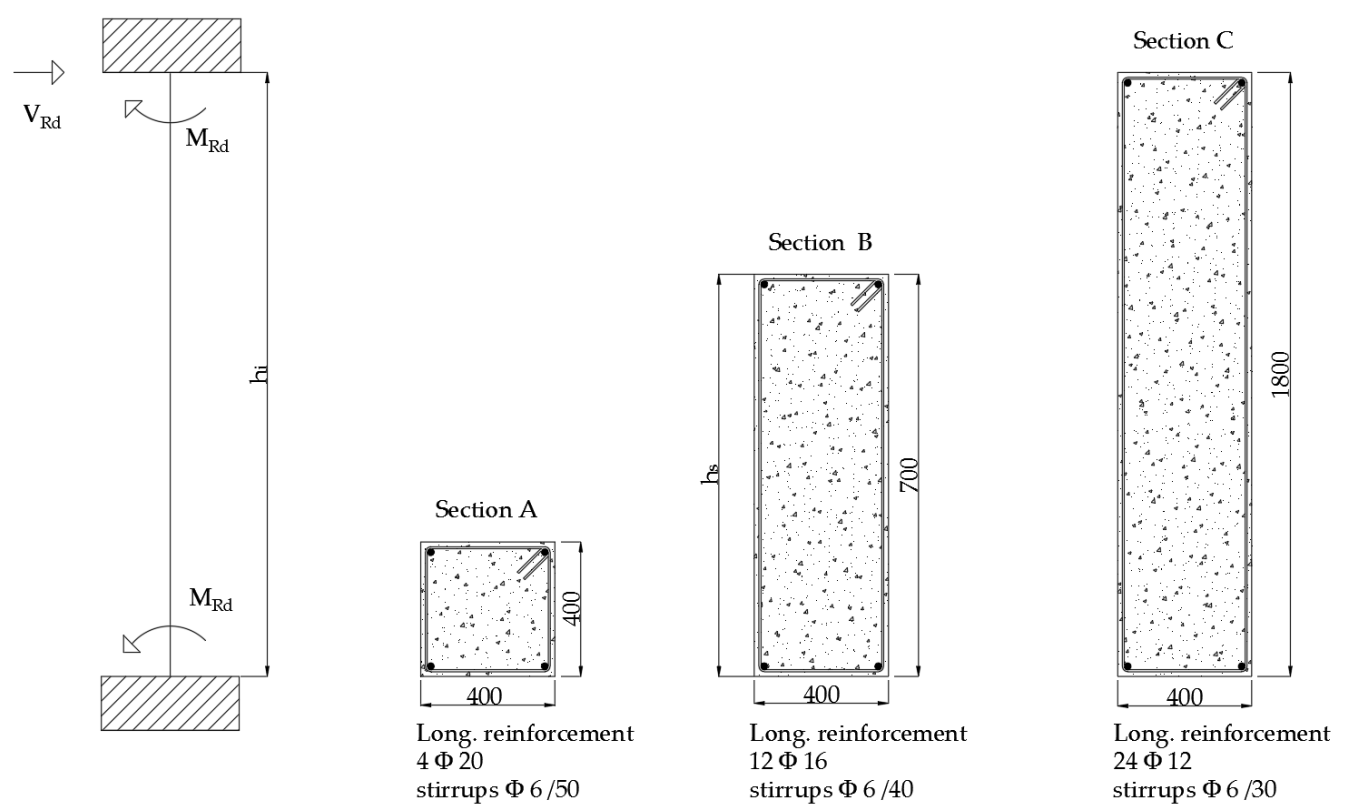

Figure 2. Considered cross sections (units in $\mathrm{mm}$ ).

Table 6. Value of $\alpha$ depending on slenderness ratio.

\begin{tabular}{cccc}
\hline Parameters & A & B & C \\
\hline$h_{i} / h_{s}$ & 8.75 & 5.00 & 1.95 \\
$\alpha$ & 2.00 & 1.55 & 1.00 \\
\hline
\end{tabular}


Table 7. Discretization of steel and concrete strength.

\begin{tabular}{ccccccc}
\hline Strength & $\mathbf{0 1}$ & $\mathbf{0 2}$ & $\mathbf{0 3}$ & $\mathbf{0 4}$ & $\mathbf{0 5}$ & Unit \\
\hline$f_{c}$ & 10 & 15 & 20 & 25 & 30 & $\mathrm{MPa}$ \\
$f_{y}$ & 230 & 260 & 290 & 320 & 350 & $\mathrm{MPa}$ \\
\hline
\end{tabular}

In case of concrete strength variation, a steel strength of $290 \mathrm{MPa}$ is fixed. In case of steel strength variation, the concrete cubic compression strength of $20 \mathrm{MPa}$ is assumed.

\subsection{Results of Parametric Analysis}

\subsubsection{Concrete}

The main results of the parametric analysis, by varying concrete strength (Table 7), are displayed in Figures 3-5. The parameters of the curves are common values of design normal force $\mathrm{N}_{\mathrm{ed}}$ acting on the columns of r.c. buildings.

Figure $3 \mathrm{a}, \mathrm{b}$ and Figure $4 \mathrm{a}$ show a nonlinear $\left(M_{R d, B}-f_{c}\right)$ behavior depending on $\left(N_{E d}\right)$.

For the considered sections, the value of the dimensionless axial stress is variable, so the slope of the respective diagrams $\left(M_{R d, B}-f_{c}\right)$ varies in the ranges of resistance. Figure $4 \mathrm{~b}$ shows that bending and shear mechanisms depend on concrete strength and the slenderness ratio.

Because of the different slope of continuous and dashed curves, a different type of failure can occur depending on the concrete strength. Figure $5 a, b$ illustrates how strength affects stiffness and curvature ductility.

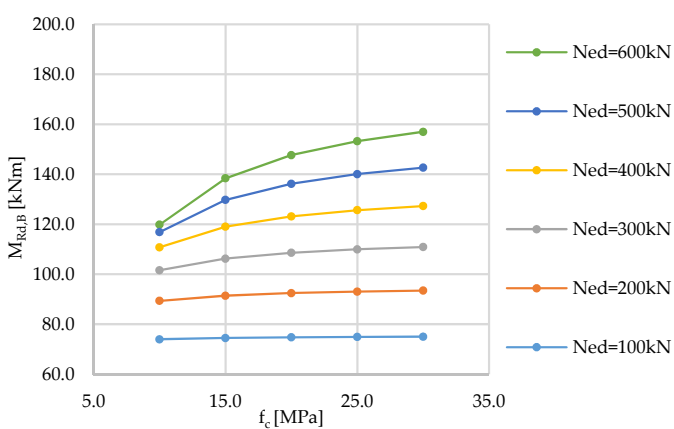

(a)

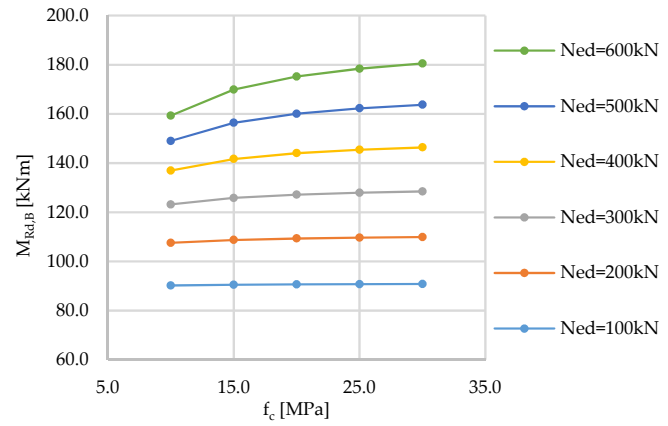

(b)

Figure 3. Bending moment of collapse $\left(\mathrm{M}_{\mathrm{Rd}, \mathrm{B}}\right)$ vs. concrete strength $\left(f_{c}\right)$ and axial force $\left(\mathrm{N}_{\mathrm{ed}}\right)$. (a) Cross section A $(40 \times 40) ;($ b $)$ Cross section B $(40 \times 70)$.

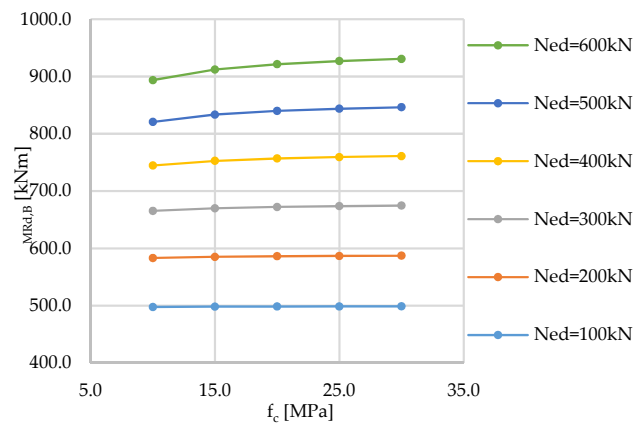

(a)

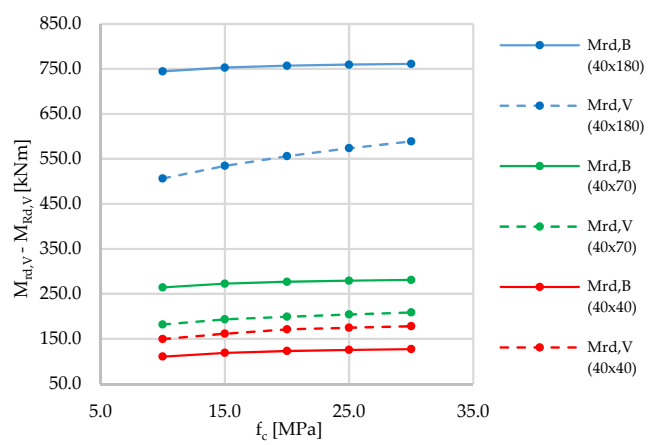

(b)

Figure 4. (a) Bending moment of collapse $\left(\mathrm{M}_{\mathrm{Rd}, \mathrm{B}}\right)$ vs. concrete strength $\left(f_{c}\right)$ and axial force $\left(\mathrm{N}_{\text {ed }}\right)$-cross section $C(40 \times 180)$; $(b)$ bending $\left(M_{R d, B}\right)$ and shear mechanism $\left(M_{R d, V}\right)$ vs. $\left(f_{c}\right)$ with $N_{e d}=400$ kN-cross section $(\mathrm{A}-\mathrm{C})$, with $\mathrm{Ned}=400 \mathrm{kN}$. 


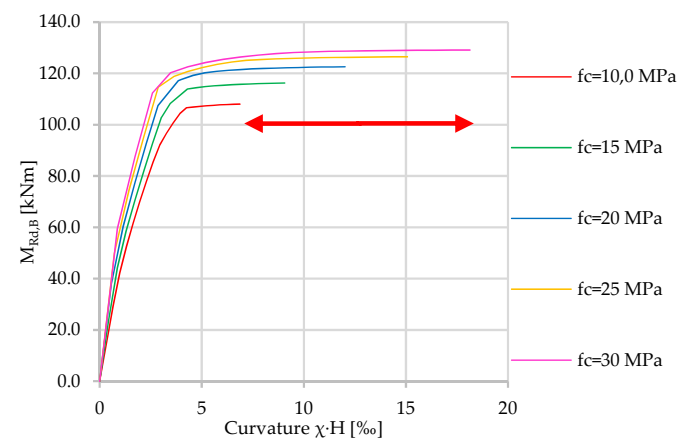

(a)

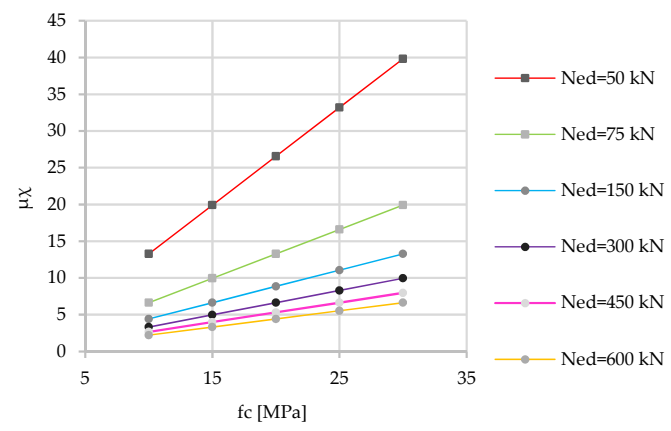

(b)

Figure 5. Bending moment $\left(\mathrm{M}_{\mathrm{Rd}, \mathrm{B}}\right)$ vs dimensionless curvature $\chi\left(h_{s}\right)$ varying concrete strength $\left(f_{c}\right)$-cross section A $(40 \times 40), \mathrm{N}_{\mathrm{ed}}=400 \mathrm{kN}(\mathbf{a})$; curvature ductility $\mu \chi$ vs. concrete strength $\left(f_{c}\right)$ and axial force $\left(\mathrm{N}_{\mathrm{ed}}\right)$-cross section $\mathrm{A}(40 \times 40)(\mathbf{b})$.

\subsubsection{Steel}

In the second set of analyses, the steel strength is varied. The main results are reported in Figures 6 and 7. It can be observed that the variation of the collapse bending moment depends linearly on the steel strength $\left(f_{y}\right)$.

In case of variation of the concrete resistance, the resistant moment of the section has a nonlinear relationship with $\mathrm{f}_{c}$, while in the case of the variation of the steel resistance, the relation is linear and the lines are parallel (Figure 6a). Therefore, in Figure 6a, only the diagram of the section $40 \times 40$ (cross sect. A) is displayed. Also, the variation of the steel resistance is shown for the graphs $\left(M_{R d, B} ; M_{R d, V}-f_{y}\right)$ of Figure $6 \mathbf{b}$ which, in this case, assumes a linear trend with respect to the case of variable concrete. The ultimate curvature and the initial stiffness do not change by varying the steel strength, affecting only the yield values (Figure 7a) [34-36]. By contrast, in the case of the variation of the compressive strength of the concrete, there is an increase of the ductility of the curvature.

A decreasing trend of curvature ductility with steel strength also occurs by varying $\mathrm{N}_{\mathrm{Ed}}$ (Figure $7 \mathrm{~b}$ ). Further parametric analyses were carried out by considering the simultaneous variation of steel and concrete strength; they did not change the main results here described, and are not reported for the sake of brevity.

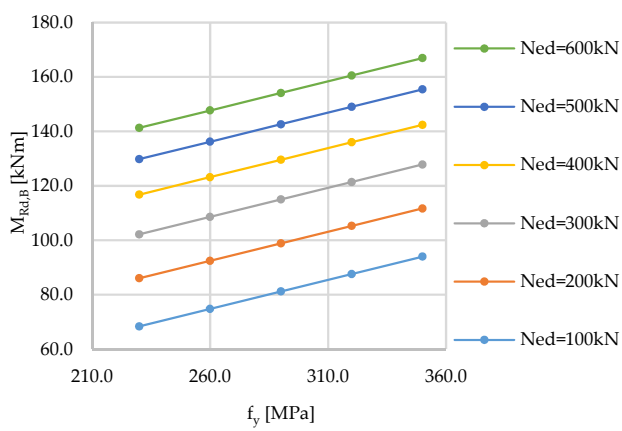

(a)

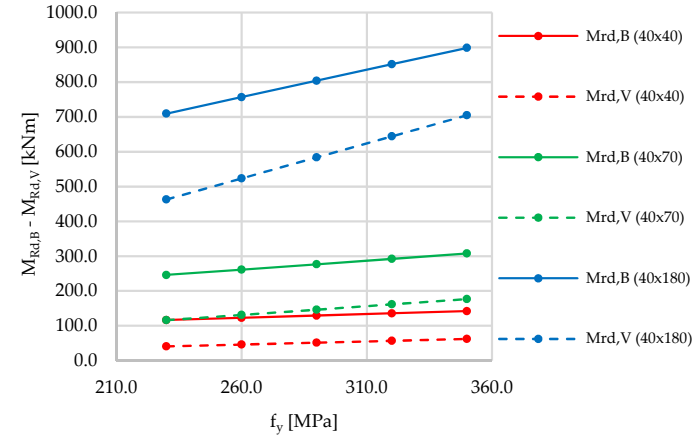

(b)

Figure 6. Bending moment of collapse $\left(\mathrm{M}_{\mathrm{Rd}}\right)$ varying steel strength $\left(f_{y d}\right)$ and axial force $\left(\mathrm{N}_{\mathrm{ed}}\right)$-cross section A $(40 \times 40)(\mathbf{a})$; cross section $(40 \times 40)$ Ductile and brittle failure mechanism of the analysed cross sections $(40 \times 40,40 \times 70,40 \times 180)$, assuming $\mathrm{N}_{\mathrm{ed}}=400 \mathrm{kN}(\mathbf{b})$. 


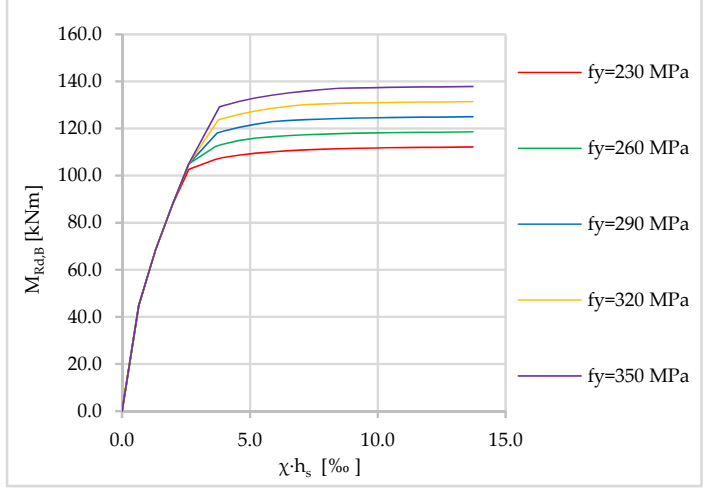

(a)

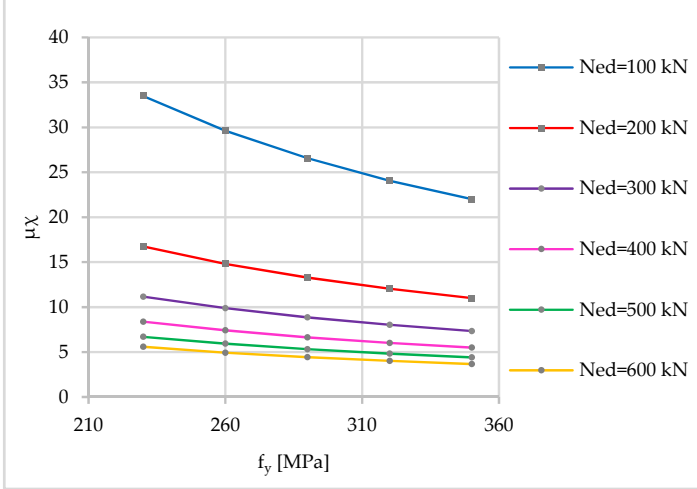

(b)

Figure 7. Bending moment $\left(\mathrm{M}_{\mathrm{Rd}}\right)$ vs. dimensionless curvature $\chi\left(\mathrm{h}_{\mathrm{s}}\right)$ varying steel strength $\left(f_{y d}\right)$-cross section A- $(40 \times 40), \mathrm{N}_{\mathrm{Ed}}=400 \mathrm{kN}(\mathbf{a})$; curvature ductility $\mu \chi$ vs. steel strength $\mathrm{f}_{\mathrm{y}}$ and axial force $\left(\mathrm{N}_{\mathrm{Ed}}\right)$-cross section $\mathrm{A}-(40 \times 40)(\mathrm{b})$.

\section{A Real Case-Study}

In this Section, the effects of material variability are investigated for a real R.C. building, taking into account the failure mechanisms illustrated in Section 4.

\subsection{Description of the Buildings}

The secondary school "Don Bosco" in Francavilla in Sinni (Potenza, Italy) is made up of two R.C. framed buildings (A and B) built in the 1970s (Figures 8 and 9).

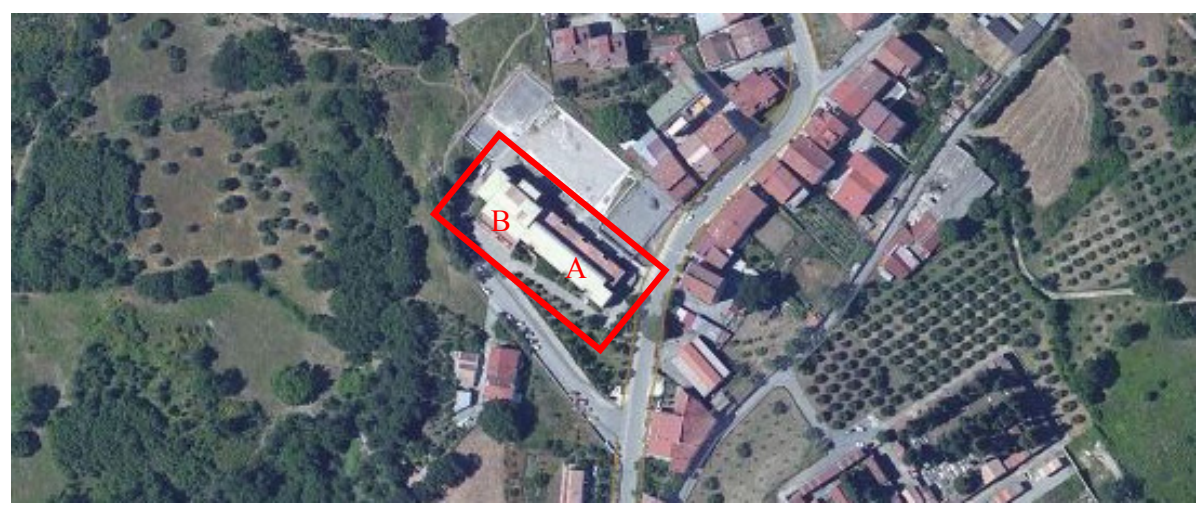

Figure 8. Aerial view of the school.

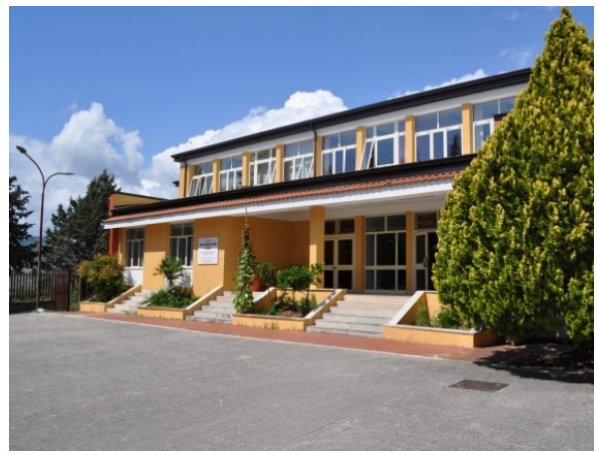

(a)

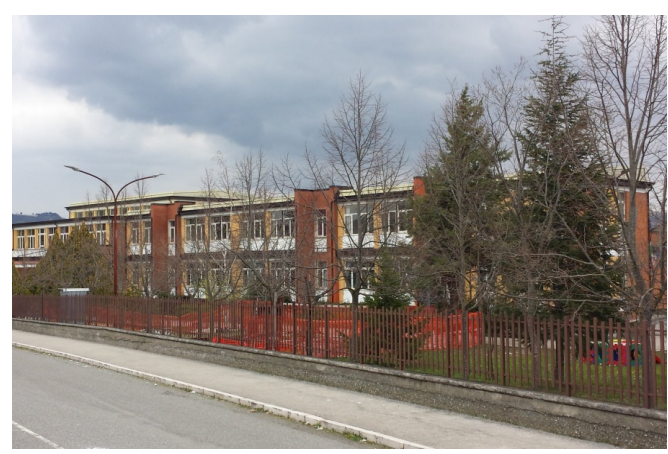

(b)

Figure 9. Main views of the school: Front entrance building B (a); building A (b). 
Building A has a rectangular shape $(45.0 \mathrm{~m} \times 16.5 \mathrm{~m})$, composed of two floors with an inter-storey height of $3.52 \mathrm{~m}$. Column cross sections are of $40 \times 40 \mathrm{~cm}^{2}$ (72\% of the total number of columns), $40 \times 70 \mathrm{~cm}^{2}(7 \%)$, and $40 \times 180 \mathrm{~cm}^{2}(21 \%)$, irregularly distributed. The structure is also irregular in elevation (with a mass reduction of $40 \%$ ).

Building $\mathrm{B}$ has an approximately squared shape with maximum in-plan dimensions of $26.0 \mathrm{~m} \times 21.0 \mathrm{~m}$, composed of three floors, one semi-basement, and two completely above the ground, with an inter-storey height of $3.52 \mathrm{~m}$ (with the exception of a central part with taller columns $(5.24 \mathrm{~m})$ ). The main frames are in both directions with r.c. and hollow-core concrete slabs with different heights $(16+4 \mathrm{~cm}$ for the offices, $42+8$ for the roof and the central corridor). Building B is also irregular, both in terms of its plan and height. Column cross sections are of $40 \times 40 \mathrm{~cm}^{2}(45 \%), 40 \times 50 \mathrm{~cm}^{2}$ (25\%), $25 \times 40 \mathrm{~cm}^{2}(20 \%)$ and $40 \times 70 \mathrm{~cm}^{2}(10 \%)$. Each building has an independent strip foundation system placed at a different level. The two structures are divided by a separating joint with insufficient width from a seismic point of view (Figure 10). Several experimental tests were made on the concrete columns of two buildings: rebound hammer, sonreb and crushing test (made on cylindrical coring samples). In particular, the experimental data of the investigations have been 11 sclerometric tests, 12 sonreb tests, and eight crushing tests on cylindrical samples of the real structure. These tests are made on the same structural elements to have more reliable values. The resulting mean data are presented in Table 8 . These data are used in two different ways: (1) extreme values (min and max) are calculated to determine the strength domain in Section 4.2.2; (2) mean value and standard deviation are used to generate random distributions of resistances (compatible with those found in situ) in order to derive fragility curves.

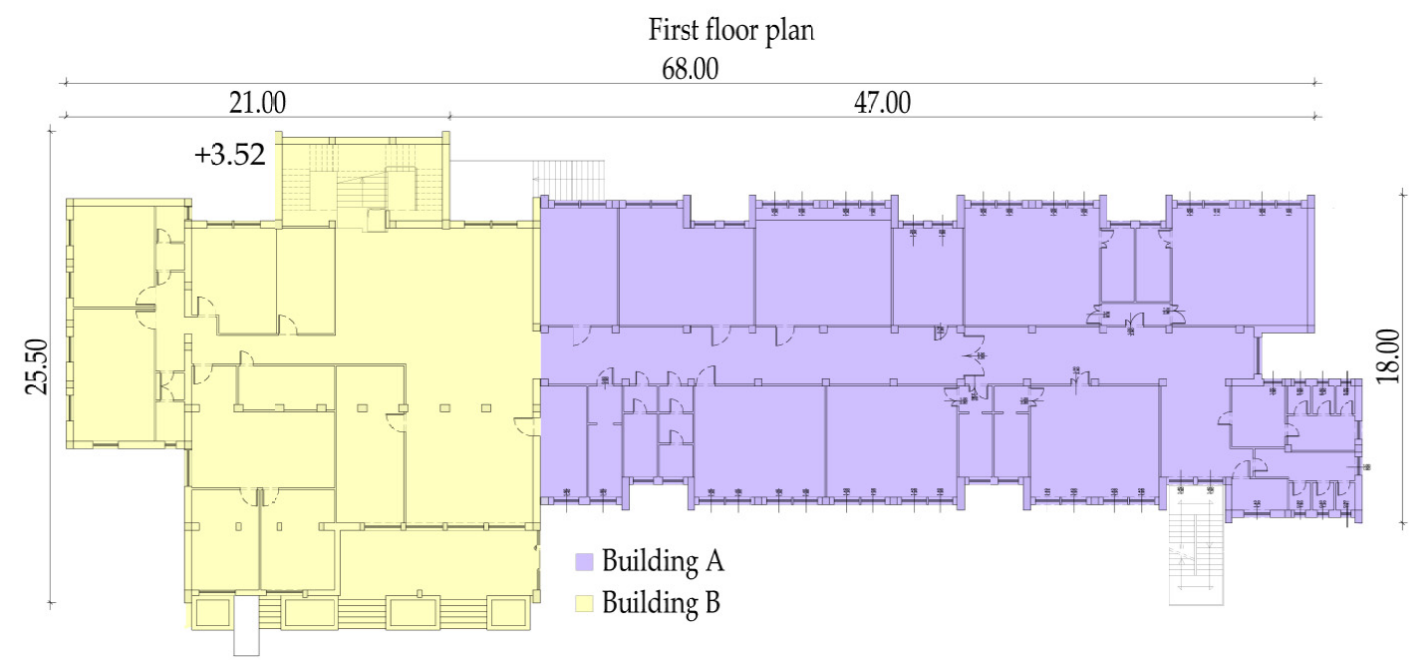

(a)

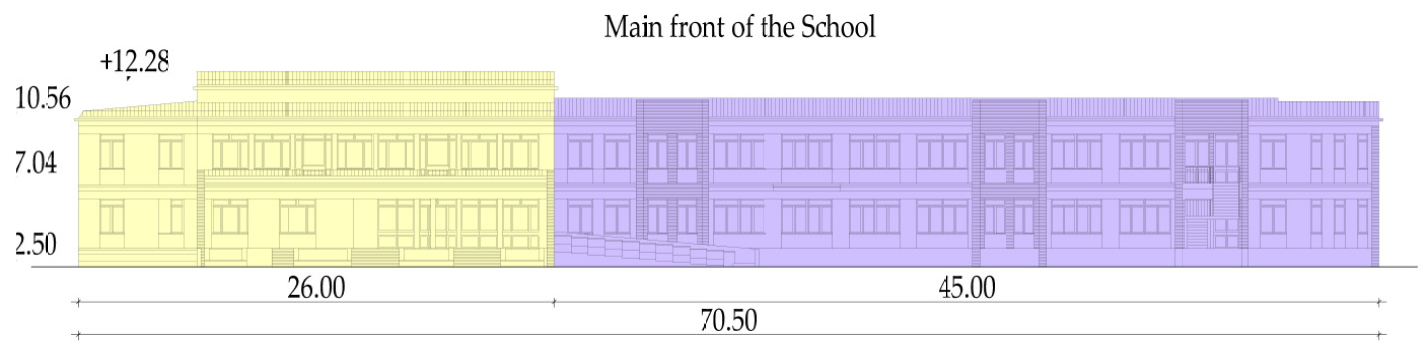

(b)

Figure 10. View of plan of the first level (a); front view (b) (units in m). 
Table 8. Experimental test carried out on the school "Don Bosco".

\begin{tabular}{ccccc}
\hline TEST & Hammer & Sonreb & Coring & Units \\
\hline 1 & 29.0 & 14.9 & 17.2 & $\mathrm{~N} / \mathrm{mm}^{2}$ \\
2 & 29.0 & 17.2 & 13.9 & $\mathrm{~N} / \mathrm{mm}^{2}$ \\
3 & 22.0 & 9.4 & 10.4 & $\mathrm{~N} / \mathrm{mm}^{2}$ \\
4 & 25.0 & 8.6 & 9.6 & $\mathrm{~N} / \mathrm{mm}^{2}$ \\
5 & 33.0 & 11.7 & 12.3 & $\mathrm{~N} / \mathrm{mm}^{2}$ \\
6 & 42.0 & 23.2 & 28.7 & $\mathrm{~N} / \mathrm{mm}^{2}$ \\
7 & 45.0 & 28.9 & 31.3 & $\mathrm{~N} / \mathrm{mm}^{2}$ \\
8 & 43.0 & 29.0 & - & $\mathrm{N} / \mathrm{mm}^{2}$ \\
9 & 38.0 & 27.5 & - & $\mathrm{N} / \mathrm{mm}^{2}$ \\
10 & 40.0 & 17.4 & - & $\mathrm{N} / \mathrm{mm}^{2}$ \\
11 & 43.0 & 22.8 & - & $\mathrm{N} / \mathrm{mm}^{2}$ \\
12 & - & 21.7 & 19.5 & $\mathrm{~N} / \mathrm{mm}^{2}$ \\
\hline
\end{tabular}

The original drawings show an improper use of stirrups, especially in the R.C. columns, and inadequate bonded lengths and overlapping of bars. All these deficiencies in structural details may cause the local brittle shear mechanism and global collapse mechanism of "weak columns"[37,38].

\subsection{Parametric Analysis}

\subsubsection{Extreme Strength Distribution}

To obtain the in-plan limit distributions of strength (that may include all the real ones), extreme values of strength are assigned to the model, and studied analogously to the models in Section 3. A vertical plane passing through the centroid of each floor subdivides it into two parts. Each distribution is obtained by rotating a vertical plane by $45^{\circ}$ around the centroid C (Figure 11), thus getting eight limit distributions of strength for the columns (Figure 11).
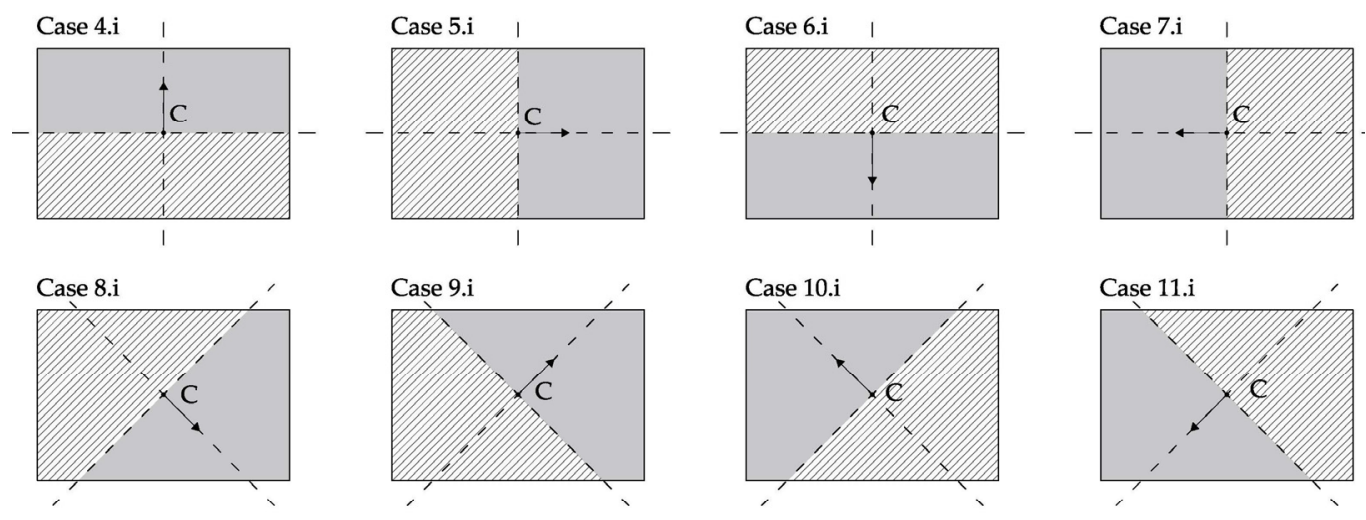

\section{- C - centroid}

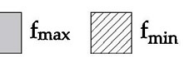

Figure 11. Extreme material distribution analysed.

The variable parameters are the concrete compression strength and the yielding strength of the steel bars. Each pair of values is assumed in both uniform and non-uniform in-plan distribution. Firstly, the two variables are considered separately. The material strengths assigned are the extreme values of Tables 4 and 5 .

In Figure 11 the subscript $i$ assumes the values 1 or 2 according to whether the variable strength is of concrete or steel, taking the other parameter constant and equal to the mean value. Cases 1.i 2.i, and 3.i are not represented in Figure 11 but are representative respectively of uniform mean, and 
the minimum and maximum value of resistance. For each configuration of strength nonlinear static analyses (NLSA) are performed.

Figures 12 and 13 show the regression between ultimate shear and eccentricity of material. The two seismic directions are separately considered and the ultimate shear in $\mathrm{x}$-direction $\left(V_{U x}\right)$ is related to the eccentricity and vice versin $y$-direction $\left(e_{m y}\right)$ (and vice versa).

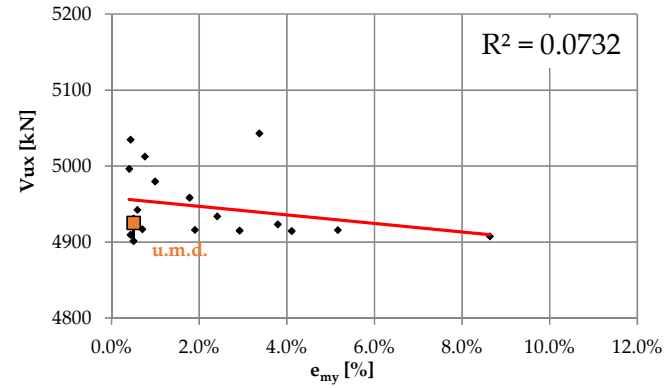

(a)

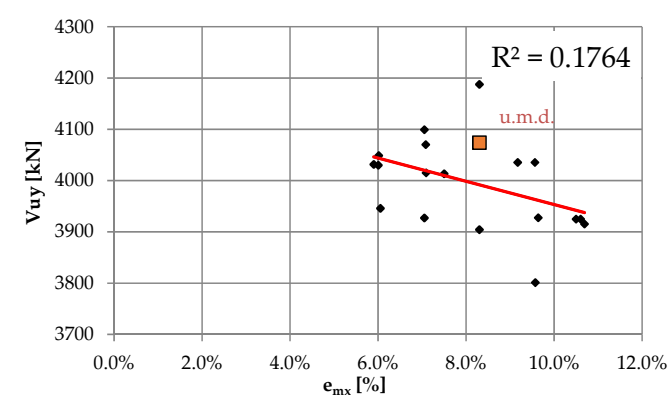

(b)

Figure 12. Linear regression $V_{u}-e_{m}$ for building A. $x$ direction (a); $y$ direction (b). The orange square with the label u.m.d. indicates the uniform material distribution case.

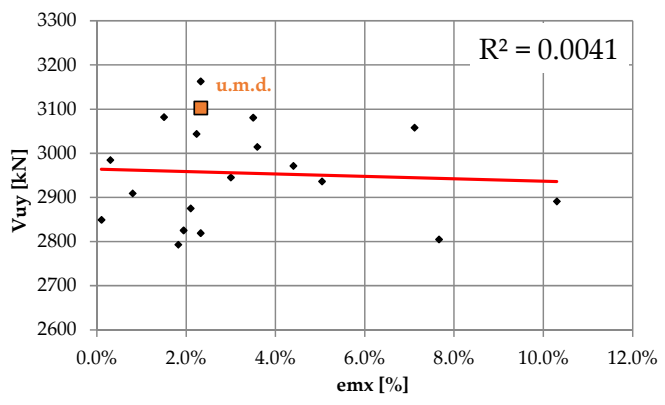

(a)

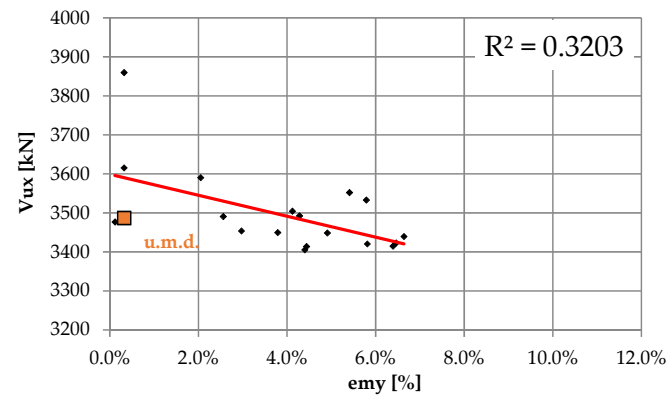

(b)

Figure 13. Linear regression $\mathrm{V}_{u}-e_{m}$ for building B. $x$ direction (a); $y$ direction (b). u.m.d. indicates the uniform material distribution case.

The elongated in-plan shape of building A produces the differences in the slope of the line that represent the relationship between $V_{U x}-e_{m y}$ and $V_{U y}-e_{m x}$ (Figure 12). In the case of building B, characterized by a compact shape, the difference between the two-coordinate direction is less remarkable.

\subsubsection{Strength Domain}

With Equations (6)-(9) it is possible to calculate the position of the resistance centers referring to the limit distributions of Figure 11. For each of these points a F.E.M. model is subjected to non-linear static (pushover) analysis to determine the risk index. It is seen that the risk index does not significantly differ from one case to another so the points represent equipotential lines for parameter $I_{R}$.

Figure 14a,b shows the domains of the center of strength for each building, obtained from the set of extreme strength distributions. They represent the material eccentricity due to extreme values of concrete strength (grey domain) or steel strength (yellow domain) by rotating the vertical plan that divides the two regions in Figure 14. 

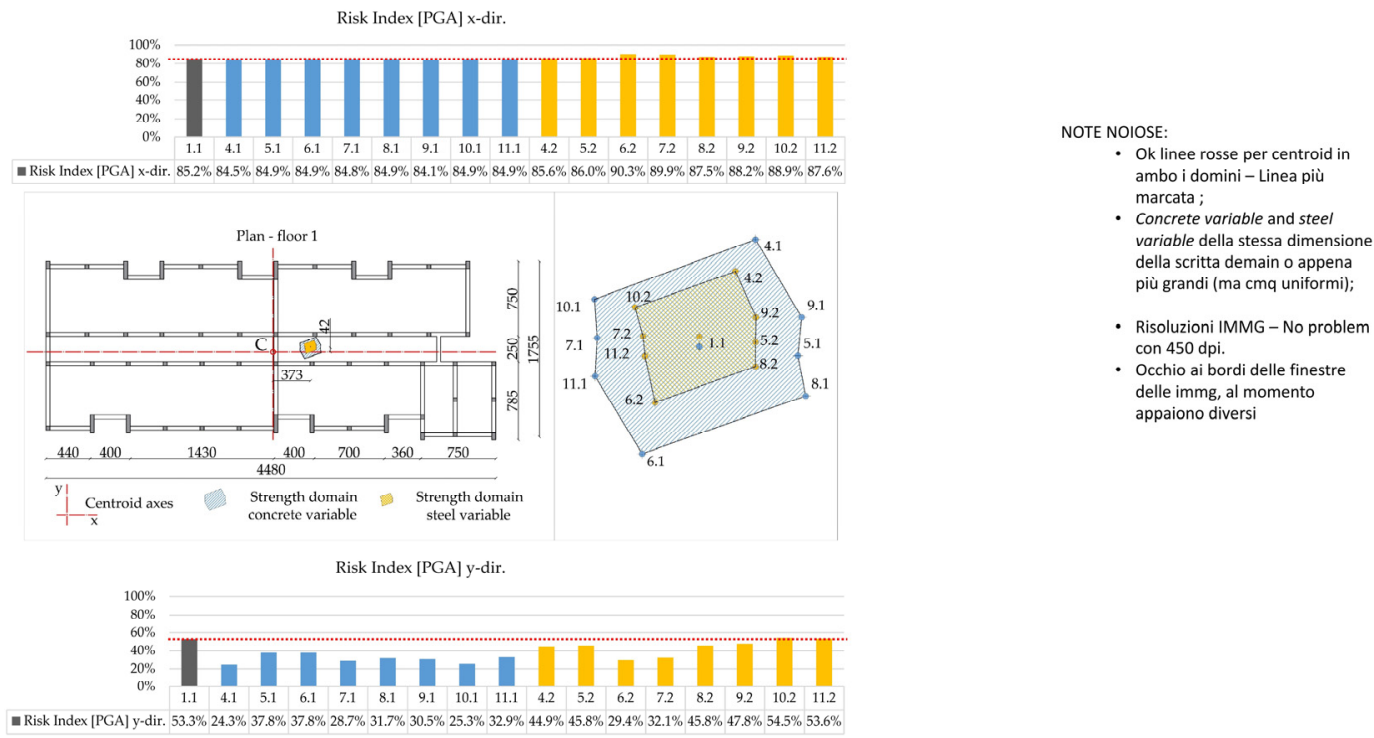

(a)

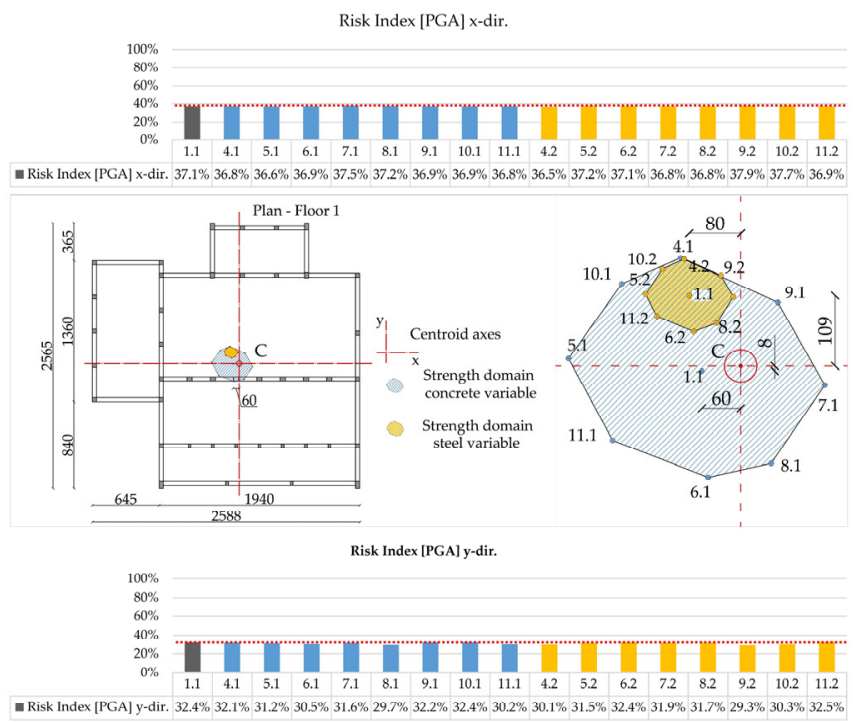

NOTE NOIOSE:

- Ok linee rosse per centroid in ambo $i$ domini (anche in SLIDE 1) - Linea rossa tratteggiata più

- Concrete variable and steel

variable della stessa dimension

della scritta demain;

Se possibile cambiare la virgola in xis (I)scra mo andrebbe fatto grigio):

()

(b)

Figure 14. Strength domain of building A (a) and B (b). At the top and at the bottom is the change rate of the risk index $I_{R}$ in $x$ and in $y$ directions (units in $\mathrm{cm}$ ). C is the centre of mass of each storey.

In this figure, the numbers in the strength domain j.i mean the following: subscript $j$ the eight cases of Figure 11, starting from 4 to 11. Cases 1-2-3 are referred to uniform distributions and are not reported for the sake of brevity. Subscript $i$ assumes the values 1 or 2 according to whether the variable strength is of concrete or steel. NLSA are carried out for both buildings. Each analysis evaluated the structural capacity relating to the border points of each domain. The main results are the variation of the index of seismic risk $I_{R}$, given by Equation (12). $I_{R}$ values are reported in the histograms of Figure 14a,b.

The results show that the risk index has a sensitive change in the shorter direction of the building, which is lower in the compact in-plan building (B), whereas along the longer direction the variation is negligible. The strength domains are greater considering the variation of concrete rather than steel. The material eccentricities are much more relevant in the irregular building, for which the strength domain does not include the centre of mass of the storey $C$. 


\subsubsection{Fragility Curves}

Finally, random material distributions are numerically generated to obtain fragility curves. The random distribution considers variation both in steel and in concrete strength. To ensure that material distribution could be realistic, a probability density function (PDF) is defined starting from the mean value and the standard deviation of strength. Two strength values (for concrete and steel) are obtained and randomly assigned to each column.

ULS and DLS (Damage Limit States) are examined. The ULS limit state is achieved for the value of PGA that determines the collapse of the structure while the DLS state is achieved for the maximum interstorey drift [13].

The steps to determine the fragility curves are $[39,40]$ :

- $\quad$ Non-Linear static analysis for each random case;

- $\quad$ PGA for each random case;

- $\quad$ Mean value $\mu P G A$ and standard deviation $\sigma P G A$ of all calculated PGA;

- Determination of the probability cumulative function (PCF) as:

$$
(x)=\Phi\left[\frac{P G A-\mu P G A}{\sigma P G A}\right]
$$

Table 9 contains the $\mathrm{P}(\mathrm{x})$ values for both buildings. The corresponding fragility curves are shown in Figure 15. The probability cumulative function PCF related to low damage is represented with the grey line; meanwhile, the one related to severe damage is represented with the black line.

Table 9. PGA values for building A and B.

\begin{tabular}{cccccc}
\hline \multirow{2}{*}{$\begin{array}{c}\text { Average Value and Standard } \\
\text { Deviation of PGA }\end{array}$} & \multicolumn{2}{c}{ Low Damage (LD) } & \multicolumn{2}{c}{ Severe Damage (SD) } \\
\cline { 3 - 6 } & PGAx & PGAy & PGAx & PGAy \\
\hline \multirow{2}{*}{ Building A } & $\mu_{P G A}$ & 0.064 & 0.064 & 0.117 & 0.093 \\
& $\sigma_{P G A}$ & 0.003 & 0.002 & 0.003 & 0.002 \\
\hline \multirow{2}{*}{ Building B } & $\mu_{P G A}$ & 0.062 & 0.006 & 0.133 & 0.093 \\
& $\sigma_{P G A}$ & 0.0007 & 0.002 & 0.134 & 0.003 \\
\hline
\end{tabular}

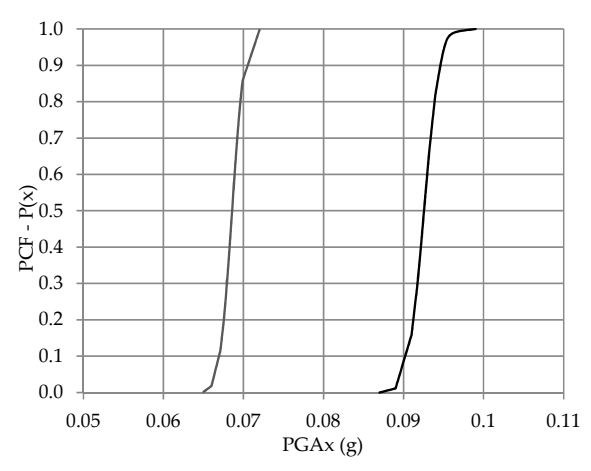

(a)

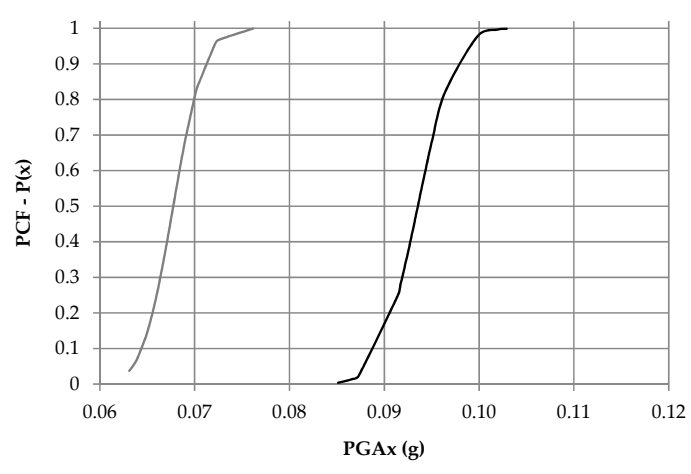

(b)

Figure 15. Fragility curves, (a) Building A; (b) Building B.

The fragility curves of Building A had a greater slope than that related to Building B. This means that Building B had a greater dispersion of the PGA values and therefore its seismic capacity is more sensitive to the material variability. The comparison of the curves (a) and (b) of Figure 15 reveals the vulnerability of building A that collapses for lower PGA values. 


\section{Conclusions}

In this paper, a simplified method to consider material variability is proposed for the seismic vulnerability assessment of existing R.C. buildings. From the consideration that concrete and steel variability can produce additional torsional effects, a material eccentricity is defined.

The illustrated methodology is based on the idea of adding a material eccentricity to those already considered in the Standards for seismic analysis. In the structural design of rehabilitation, as shown in the examples, it is easy to take into account the variability of the mechanical parameters.

Several nonlinear analyses are performed on a benchmark example and on two real case-studies of R.C. frames. The effects on the risk indexes and on collapse mechanisms are discussed. Extreme strength distributions are considered leading to the definition of a strength domain, varying concrete and steel strength separately. These domains can be considered as contour lines of the seismic risk index.

For the benchmark model, the results showed that in the case of non-uniform material distribution the ratio of capacity to demand in terms of PGA and the ultimate displacement capacity decreased. For the real case study, the risk index was observed to have a sensitive change in the shorter direction of the building, whereas along the longer direction the variation is negligible. The strength domains are greater considering the variation of concrete rather than steel. The material eccentricities are much more relevant in the irregular building, for which the strength domain do not include the centre of mass of the storey.

Further investigations could be carried out on similar structures by considering random and/or real strength distributions, evaluating the changes in the strength domain. Further studies can be addressed to evaluating which types of buildings can be more sensitive to material variability, with the aim of properly taking this into account for the evaluation of the seismic capacity.

Acknowledgments: The authors thank the Municipal Authorities of Francavilla in Sinni (PZ) and the Technical Staff Eng. Gaetano Chiurazzi and Surveyor Antonio Puppio for the support and the experimental data. Thanks to Eng. Costanza Micheli for the editorial support.

Author Contributions: M.L.P. conceived and wrote the paper. M.P. Performed structural analysis and managed experimental data. L.G. and M.S. contributed to write the paper and improved its structure proposing analytical tools. The Paper widely derived from the Master Thesis Seismic vulnerability and a proposal of seismic improvement of the building Middle School "Don Bosco" in Francavilla in Sinni (PZ) - Italy (Author: M.P.; Supervisors: M.S. and M.L.P).

Conflicts of Interest: The authors declare no conflict of interest.

\section{Appendix A}

The Symbols of the equations (13)-(16) are described below:

B coefficient equal to: 0.81 ;

$\alpha \quad$ coefficient equal to: 0.83 ;

$b \quad$ width of the section;

$A_{s} \quad$ area of the longitudinal steel reinforcement;

$h$ height of the section;

c filler tiles;

$C_{R d, c} \frac{0.15}{\gamma_{c}}$

$k \quad 1+\sqrt{\frac{200}{d}} ;$

$\rho_{l} \quad$ ratio of longitudinal steel reinforcement;

$k_{1} \quad$ coefficient equal to: 0.15 ;

$\sigma_{c p}$ mean compressive stress in the section due to axial force;

$b_{w} \quad$ minimum width of the section; 
$d \quad$ internal height of the section;

$A_{s w}$ transverse area of the stirrups;

$s \quad$ spacing between the stirrups;

$z \quad$ moment arm;

$f_{y w d} \quad$ strength of the stirrups;

$\theta \quad$ inclination of the concrete struts;

$\alpha_{c w} \quad$ coefficient equal to: 1 ;

$v_{1} \quad 0.5\left(1-f_{l c k} / 250\right)$.

For further details see: BS EN 1992-1-1 2004.

\section{References}

1. Marie-Victoire, E.; Cailleux, E.; Texier, A. Carbonation and historical buildings made of concrete. J. Phys. IV Fr. 2006, 136, 305-318. [CrossRef]

2. Glasser, F.P.; Marchand, J.; Samson, E. Durability of concrete-Degradation phenomena involving detrimental chemical reactions. Cem. Concr. Res. 2008, 38, 226-246. [CrossRef]

3. Parisi, F.; Augenti, N. Influence of seismic design criteria on blast resistance of RC framed buildings: A case study. Eng. Struct. 2012, 44, 78-93. [CrossRef]

4. Parisi, F.; Augenti, N. Seismic capacity of irregular unreinforced masonry walls with openings. Earthq. Eng. Struct. Dyn. 2013, 42, 101-121. [CrossRef]

5. Tubaldi, E.; Barbato, M.; Dall'Asta, A. Seismic Response and Vulnerability of Steel-Concrete Composite Bridges Accounting for Model Parameter Uncertainties. Struct. Congr. 2010 2010, 1840-1851. [CrossRef]

6. Badalassi, M.; Braconi, A.; Cajot, L.G.; Caprili, S.; Herve, D.; Gundel, M.; Hjiaj, M.; Hoffmeister, B.; Karamanos, S.A.; Salvatore, W.; et al. Influence of variability of material mechanical properties on seismic performance of steel and steel-concrete composite structures. Bull. Earthq. Eng. 2016. [CrossRef]

7. Zelaschi, C.; Monteiro, R.; Pinho, R. Parametric Characterization of RC Bridges for Seismic Assessment Purposes. Structures 2016, 7, 14-24. [CrossRef]

8. Giresini, L.; Sassu, M. Tests Results and Simple Structural Analysis of the Main Lighthouse in the Harbor of Livorno (Italy). Adv. Mater. Res. 2013, 834-836, 1299-1303. [CrossRef]

9. Rovero, L.; Alecci, V.; Mechelli, J.; Tonietti, U.; De Stefano, M. Masonry walls with irregular texture of L'Aquila (Italy) seismic area: validation of a method for the evaluation of masonry quality. Mater. Struct. 2015, 49. [CrossRef]

10. Muller, D.; Forster, V.; Graunbner, C.-A. Influence of Material Spatial Variability on the Reliability of Masonry Walls in Compression. In Proceedings of the 13th Canadian Masonry Symposium, Halifax, NS, Canada, 4-7 June 2017.

11. Viti, S.; Tanganelli, M.; De Stefano, M. Seismic performance sensitivity to concrete strength variability: A case-study. Earthq. Struct. 2015, 9, 321-337. [CrossRef]

12. Alecci, V.; De Stefano, M.; Luciano, R.; Rovero, L.; Stipo, G. Experimental Investigation on Bond Behavior of Cement-Matrix-Based Composites for Strengthening of Masonry Structures. J. Compos. Constr. 2015, 20. [CrossRef]

13. Alecci, V.; Focacci, F.; Rovero, L.; Stipo, G.; De Stefano, M. Extrados strengthening of brick masonry arches with PBO-FRCM composites: Experimental and analytical investigations. Compos. Struct. 2016, 149, 184-196. [CrossRef]

14. Alecci, V.; Misseri, G.; Rovero, L.; Stipo, G.; De Stefano, M.; Feo, L.; Luciano, R. Experimental investigation on masonry arches strengthened with PBO-FRCM composite. Compos. Part B Eng. 2016. [CrossRef]

15. Sassu, M.; De Falco, A. Legal disputes and building defects: some data from Tuscany (Italy). J. Perform. Constr. Facil. 2013, 28, 1-32.

16. Alecci, V.; Briccoli Bati, S.; Ranocchiai, G. Study of Brick Masonry Columns Confined with CFRP Composite. J. Compos. Constr. 2009, 13, 179-187. [CrossRef]

17. De Falco, A.; Froli, M.; Giresini, L.; Puppio, M.L.; Sassu, M. A proposal for the consolidation of a r.c. social housing by means of external hybrid steel-glass frameworks. Appl. Mech. Mater. 2014, 638-640, 3-8. [CrossRef] 
18. Alecci, V.; Briccoli Bati, S.; Ranocchiai, G. Numerical homogenization techniques for the evaluation of mechanical behaviour of a composite with SMA inclusions. J. Mech. Mater. Struct. 2009, 4, 1675-1688. [CrossRef]

19. Alecci, V.; Bati, S.B.; Ranocchiai, G. Concrete columns confined with CFRP wraps. Mater. Struct. 2014, 1-14. [CrossRef]

20. EN 1998-1 EN 1998-1: Eurocode 8-Design of structures for earthquake resistance. Part 1: General rules, seismic actions and rules for buildings. CEN 2004, 1, 1-229.

21. Giresini, L.; Gioeli, A.; Sassu, M. Seismic Reinforcement of a r.c. Building with External Steel Frameworks: The Case of the Primary School XXV April of Arcola (Italy). Adv. Mater. Res. 2013, 834-836, 697-700. [CrossRef]

22. Lavan, O.; de Stefano, M. Geotechnical, Geological and Earthquake Engineering. Geotech. Geol. Earthq. Eng. 2013, 24. [CrossRef]

23. Biondini, F.; Bontempi, F.; Frangopol, D.M.; Malerba, P.G. Probabilistic service life assessment and maintenance planning of concrete structures. J. Struct. Eng. 2006, 132, 810-825. [CrossRef]

24. Fajfar, P.; Marusic, D.; Perus, I. Torsional Effects in the Pushover-Based Seismic Analysis of Buildings. J. Earthq. Eng. 2005, 9, 831-854. [CrossRef]

25. De-la-Colina, J.; Alberto González-Pérez, C.; Valdés-González, J. Accidental eccentricities, frame shear forces and ductility demands of buildings with uncertainties of stiffness and live load. Eng. Struct. 2016, 124, 113-127. [CrossRef]

26. De Stefano, M.; Pintucchi, B. A review of research on seismic behaviour of irregular building structures since 2002. Bull. Earthq. Eng. 2008, 285-308. [CrossRef]

27. De la Llera, J.C.; Chopra, A.K. Accidental torsion in buildings due to base rotational excitation. Earthq. Eng. Struct. Dyn. 1994, 23, 1003-1021. [CrossRef]

28. De Stefano, M.; Pintuchi, B. Predicting torsion-induced lateral displacements for pushover analysis: Influence of torsional system characteristics. Earthq. Eng. Struct. Dyn. 2010, 39, 1369-1394. [CrossRef]

29. Shibin, L.; Lili, X.; Maosheng, G.; Ming, L. Performance-based methodology for assessing seismic vulnerability and capacity of buildings. Earthq. Eng. Eng. Vib. 2010, 9, 157-165. [CrossRef]

30. Chopra, A.K.; Goel, R.K. A modal pushover analysis procedure to estimate seismic demands for unsymmetric-plan buildings. Earthq. Eng. Struct. Dyn. 2004, 33, 903-927. [CrossRef]

31. Chopra, A.K.; Goel, R.K. A modal pushover analysis procedure for estimating seismic demands for buildings. Earthq. Eng. Struct. Dyn. 2002, 31, 561-582. [CrossRef]

32. Ricker, N. Further developments in the wavelet theory of seismogram structure. Bull. Seism. Soc. Am. 1943, 33, 197-228.

33. Verderame, G.M.; Stella, A.; Cosenza, E. Le proprietà meccaniche degli acciai impiegati nelle strutture in c.a. realizzate negli anni '60. In Proceedings of the X Congresso Nazionale "L'Ingegneria Sismica in Italia-ANIDIS, Potenza-Matera, Italy, 9-13 September 2001.

34. Zhou, J.; He, F.; Liu, T. Curvature ductility of columns and structural displacement ductility in RC frame structures subjected to ground motions. Soil Dyn. Earthq. Eng. 2014, 63, 174-183. [CrossRef]

35. Arslan, M.H. Estimation of curvature and displacement ductility in reinforced concrete buildings. KSCE J. Civ. Eng. 2012, 16, 759-770. [CrossRef]

36. Biondini, F.; Camnasio, E.; Titi, A. Seismic resilience of concrete structures under corrosion. Earthq. Eng. Struct. Dyn. 2015, 44, 2445-2466. [CrossRef]

37. Augenti, N.; Parisi, F. Learning from Construction Failures due to the 2009 L'Aquila, Italy, Earthquake. J. Perform. Constr. Facil. 2010, 24, 536-555. [CrossRef]

38. Andreini, M.; De Falco, A.; Giresini, L.; Sassu, M. Structural damage in the cities of Reggiolo and Carpi after the earthquake on May 2012 in Emilia Romagna. Bull. Earthq. Eng. 2014. [CrossRef]

39. Vona, M. Fragility Curves of Existing RC Buildings Based on Specific Structural Performance Levels. Open J. Civ. Eng. 2014, 4, 120-134. [CrossRef]

40. Rota, M.; Penna, A.; Strobbia, C.L. Processing Italian damage data to derive typological fragility curves. Soil Dyn. Earthq. Eng. 2008, 28, 933-947. [CrossRef]

(C) 2017 by the authors. Licensee MDPI, Basel, Switzerland. This article is an open access article distributed under the terms and conditions of the Creative Commons Attribution (CC BY) license (http:/ / creativecommons.org/licenses/by/4.0/). 